\title{
INDICAÇÃO GEOGRÁFICA NA CONSERVAÇÃO E AGREGAÇÃO DE VALOR AO GADO CURRALEIRO DA COMUNIDADE KALUNGA
}

\author{
GEOGRAPHICAL INDICATION IN CONSERVATION AND VALUE AGGREGATION TO \\ CURRALEIRO CATTLE OF THE KALUNGA COMMUNITY
}

\author{
Neiva, A.C.G.R. ${ }^{1}$, Sereno, J.R.B. ${ }^{2}$ e Fioravanti, M.C.S. ${ }^{3}$ \\ ${ }^{1}$ Universidade Federal do Tocantins. Araguaína. Tocantins. Brasil. aclaudianeiva@gmail.com \\ ${ }^{2}$ Embrapa Cerrados. Planaltina Distrito Federal. Brasil. sereno@cpac.embrapa.br \\ 3Universidade Federal de Goiás. Escola de Veterinária. Goiânia. Goiás. Brasil. clorinda@vet.ufg.br
}

\section{PaLAVRAS CHAVE ADICIONAIS}

Denominação de origem. Desenvolvimento local. Pé-Duro. Propriedade intelectual. Quilombolas.

\section{RESUMO}

Este trabalho objetivou mostrar a importância das indicações geográficas, como estratégia de conservação e agregação de valor ao gado Curraleiro e, propor estratégias para o futuro registro da denominação de origem Carne de Curraleiro Kalunga, pela comunidade remanescente de quilombo Kalunga do município de Cavalcante, Goiás, Brasil. O reconhecimento da denominação de origem Carne de Curraleiro Kalunga, viabilizará o estabelecimento de uma modalidade de exploração sustentável para o Cerrado, com a preservação de uma raça bovina adaptada as condições adversas deste bioma e proporcionará às famílias quilombolas, melhoria na disponibilidade de alimento e aumento da renda familiar.

\section{SUMMARY}

The objective of this study was to show the importance of geographical indications, as a strategy of maintaining and aggregating value to the Curraleiro cattle, and as a basis for future registration of the denomination of origin Kalunga Meat of Curraleiro, by the remaining Kalunga quilombo community in Cavalcante situated in the State of Goiás, Brazil. Recognition of the denomination of origin Kalunga Meat of Curraleiro, will make establishment of a modality of sustainable exploration in the Cerrado possible, as well as promote preservation of a bovine race well adapted

Presentado al Congreso SERGA (2010, Asturias).

\section{AdDitionAL KEYWORDS}

Denomination of origin. Local development. PéDuro. Intellectual property. Quilombolas.

to adverse conditions of this biome, improve their food availability and increase family income.

\section{INTRODUÇÃO}

As indicações geográficas (IG) são formas de diferenciação e agregação de valor ao produto, pois incorporam ao mesmo, a história da região, a cultura, o saber fazer e a identidade local, oferecendo ao consumidor um sinal de sua tipicidade e qualidade. Podem ser utilizadas como ferramentas de políticas públicas para organização do território, conservação da biodiversidade e estímulo à agricultura familiar (Santilli, 2006; Silva et al., 2008).

Além dos benefícios citados, a IG pode ser utilizada como uma estratégia de viabilização de alternativas sustentáveis para o bioma Cerrado, por meio do estabelecimento de sistemas de produção ambientalmente corretos, gerando ocupação e renda para populações próximas às áreas de preservação. A criação de uma raça bovina local ou naturalizada, de forma extensiva, alimentada com vegetação nativa, adaptada as condições do Cerrado, torna-se ideal para sistemas de produção agroecológicos em decorrência de sua resistência natural a patógenos. E ainda apresenta a vantagem 
de possuir sabor diferenciado em sua carne, o que pode ser utilizado como uma alternativa viável de geração de renda para a comunidade quilombola Kalunga, que vive em condições de extrema dificuldade, com nítido declínio das atividades agropecuárias e, portanto, de comercialização de produtos (Oliveira e Duarte, 2004; Fioravanti et al., 2008).

O presente trabalho teve como objetivo apontar a importância das indicações geográficas, especificamente, as denominações de origem, como estratégia de conservação e agregação de valor ao gado Curraleiro, e ao mesmo tempo propor as estratégias necessárias ao registro da denominação de origem pela comunidade quilombola Kalunga.

\section{MATERIAISE MÉTODOS}

\section{CARACTERIZAÇÃo DO TERRITÓRIO E DO} PRODUto CARNEDE CURRALEIRO KaLUNGA

O território no qual se pretende implementar a Denominação de Origem Carne de Curraleiro Kalunga, corresponde, a área do Sítio Histórico e Patrimônio Cultural Kalunga, na microrregião Chapada dos Veadeiros, nordeste do Estado de Goiás, Brasil. A comunidade Kalunga é a comunidade remanescente de quilombo mais importante em termos numérico e histórico da região Centro-Oeste e está entre as maiores do país. Ocupa uma área de 253,2 mil hectares nos municípios de Cavalcante, Monte Alegre e Teresina de Goiás, com uma população estimada em aproximadamente quatro mil habitantes (Anjos e Cypriano, 2006).

A Denominação de Origem Carne de Curraleiro Kalunga, será implementada utilizando bovinos da raça Curraleiro, como são conhecidos em Goiás e no Tocantins ou Pé-Duro, nome dado em algumas regiões do Nordeste. As raças bovinas locais do Brasil foram originadas de raças procedentes da Península Ibérica trazidas para o país pelos colonizadores à época do descobrimento.
Estas raças passaram por um processo de seleção natural e se adaptaram às condições climáticas, sanitárias e de manejo em diferentes regiões do país, adquirindo características como rusticidade, prolificidade e resistência a ecto e endoparasitas. Assim, a busca por raças mais produtivas, especialmente no início do século XX, fez com que raças exóticas, especialmente as zebuínas, selecionadas em países de clima temperado, fossem importadas, e gradativamente fossem substituindo as raças locais, o que provocou quase que o desaparecimento dessas raças (Mariante e Egito, 2002). Dentre as raças bovinas locais brasileiras ameaçadas de extinção encontra-se o gado Curraleiro o Pé-Duro. Estes animais estão distribuídos nos estados do Maranhão, Piauí, Tocantins e Goiás e estima-se que existam mais de 5000 exemplares. A Empresa Brasileira de Pesquisa Agropecuária (EMBRAPA) possui um núcleo de preservação em São João do Piauí, Estado do Piauí (Fioravanti et al., 2008). Adaptado às condições adversas do Cerrado, o bovino Curraleiro possui carne saborosa. Além disso, sua rusticidade e maior resistência a certas doenças e parasitos, minimizam o uso de insumos químicos como medicamentos e carrapaticidas, o que viabiliza a utilização da raça em sistemas de produção naturais (Carvalho, 1997).

Num contexto globalizado, a política da União Européia que dá suporte a agricultura sustentável tem gerado um novo interesse nas raças locais frente aos novos desafios de produção de carne. Nos últimos anos vários trabalhos têm sido desenvolvidos objetivando caracterizar o sistema de produção, a carcaça e a carne de raças locais para servir de base para a construção de uma marca de qualidade, baseada em uma raça ou em um produto específico (Perea et al., 2007; Gonzalez et al., 2009; Panea et al., 2010; Nogales et al., 2011).

O mercado consumidor de carne bovina no mundo todo aponta para um novo padrão de demanda, com ênfase na qualidade e 
segurança dos alimentos, além da percepção dos problemas ambientais decorrentes do sistema tradicional de produção e a exigência de sistemas produtivos que sejam concomitantemente socialmente justos, economicamente viáveis e ambientalmente sustentáveis (Ramos Filho, 2006). Para garantir a qualidade do produto é importante agregar informações sobre a sua base genética. Os marcadores moleculares representam uma importante ferramenta no melhoramento genético, pois permitem a identificação dos genes que influenciam as características produtivas (Motter et al., 2009). Especificamente em relação ao desenvolvimento de produtos de qualidade, também são importantes, uma vez que já estão descritos marcadores moleculares ligados a maciez de carne como a calpaína e calpastatina (Lara et al., 2005; Luciano et al., 2007; Motter et al., 2009).

\section{OrganIZAÇÃO SOCIAL EARTICULAÇÃOdOS PRODUTORES}

A Associação Kalunga de Cavalcante (AKC), fundada em 26 de agosto de 2004 e atualmente com cerca de 300 associados, será a entidade detentora da tutela da IG Carne de Curraleiro Kalunga e deverá encaminhar a solicitação do reconhecimento ao Instituto Nacional de Propriedade Intelectual (INPI).

Em 2006 a Universidade Federal de Goiás (UFG) foi convidada pelo Ministério da Integração Nacional a esboçar um projeto que correlacionasse o Gado Curraleiro e os Kalungas. Desta parceria nasceu o projeto, Estabelecimento e Manutenção de Núcleos de Criação de Gado Curraleiro. Como estratégia de reintrodução do gado Curraleiro e resgate da tradição na região, em junho de 2007, dez famílias Kalungas e o Núcleo de Criação de Curraleiro receberam 86 animais (Fioravanti et al., 2008).

\section{IMPLEMENTAČ̃̃ DO PROJETO CARNE DE Curraleiro Kalunga}

A primeira etapa da proposta de implementação da DO Carne de Curraleiro Kalunga terá inicio com a realização de uma oficina de trabalho para discussão e esclarecimento sobre os requisitos necessários para o reconhecimento de uma DO.

A segunda etapa a ser cumprida é um estudo detalhado da região que ajudará na definição do território da DO. Será parte integrante do estudo a caracterização geográfica da região, assim como os documentos históricos que comprovem que o gado Curraleiro já foi criado por inúmeros produtores da região.

Na terceira etapa será efetuado um trabalho com os produtores, tomadores de decisão da região, técnicos e instituições públicas e privadas ligadas a cadeia produtiva do produto, visando o detalhamento das estratégias de ação e definição dos padrões de qualidade a serem adotados. As normas aqui estabelecidas farão parte do Regulamento de Uso, requisito essencial para o registro da $\mathrm{DO}$, e que garante ao consumidor a qualidade e tradição do produto adquirido.

Na quarta etapa será criado um Conselho Regulador, composto por produtores, técnicos especializados e por instituições públicas e privadas afetas ao produto, que representará institucionalmente a DO, além de orientar, coordenar e fiscalizar a produção e a comercialização do produto (Locatelli, 2007).

A última etapa do processo de implementação da DO é o encaminhamento do pedido de reconhecimento ao INPI. Durante todas as etapas serão desenvolvidas atividades de sensibilização capacitação e mobilização de todos os atores envolvidos no processo, além de um trabalho de marketing junto aos consumidores.

\section{CONCLUSÕES}

O reconhecimento da DO Carne de Curraleiro Kalunga viabilizará o estabelecimento de uma modalidade de exploração sustentável do Cerrado e auxiliará na 
preservação de uma raça bovina perfeitamente adaptada às condições adversas desse ecossistema. Além desses fatores, proporcionará a manutenção da tradição pecuária com melhoria na disponibilidade

\section{BIBLIOGRAFIA}

Anjos, R.S.A. e Cypriano, A. 2006. Quilombolas: tradições e cultura da resistência. Aori Comunicação. São Paulo. 240 pp.

Carvalho, J.H. de. 1997. Potencial econômico do bovino Pé-Duro. Embrapa Meio Norte (Documentos). Teresina. № 26: 1-3.

Fioravanti, M.C.S., Sereno, J.R.B., Neiva, A.C.G.R., Abud, L.J., Lobo, J.R., Francescantônio, D.D., Cardoso, W.S., Silva, F.X. e Machado, J.R.L. 2008. Reintrodução do gado Curraleiro na comunidade quilombola Kalunga de Cavalcante, Goiás, Brasil. Resultados parciais. Em: Simpósio Nacional do Cerrado, 9. Simpósio Internacional de Savanas Tropicais, 2. Brasília. Anais..., EMBRAPA. Brasília.

González, L., Moreno, T., Bispo, E., Latorre, A., Mendez, J., Llena, J. y Franco, D. 2009. Estudio de la maduración de la carne de ternera de raza Rubia Gallega: tipo de pieza y clase animal. Arch. Zootec., 58: 565-568.

Lara, M.A.C., Nardon, R.F., Bufarah, G., Demarchi, J.J.A.A., Sereno, J.R., Santos, S.A. y Abreu, U.G.P. 2005. Polimorfismo del gen calpaína en razas vacunas por la técnica PCR-RFLP. Arch. Zootec., 54: 305-310.

Locatelli, L. 2007. Indicações geográficas: a proteção jurídica sob a perspectiva do desenvolvimento econômico. Juruá Editora. Curitiba. 338 pp.

Luciano, F.B., Anton, A.A. and Rosa, C.F. 2007. Biochemical aspects of meat tenderness: a brief review. Arch. Zootec., 56: 1-8.

Mariante, A.S. and Egito, A.A. 2002. Animal genetic resources in Brazil: result of five centuries of natural selection. Theriogenology, 57: 223-235. Motter, M.M., Corva, P., Krause, M., Perez Cenci, M. y Soria, L. 2009. Rol de la calpastatina en la variabilidad de la terneza de la carne bovina. $J$. de alimento, incremento da renda familiar, melhorando a segurança alimentar das famílias, a qualidade de vida e o bem-estar da população, o que refletirá em melhorias para a região como um todo.

Basic Appl. Genet., 20: 15-24.

Nogales, S., Bressan, M.C., Vaz, A.P., Delgado, J.V. y Camacho, M.E. 2011. Estudio físicoquímico de la carne de la raza bovina Marismeña en diferentes sistemas de terminación. Arch. Zootec., 60: 1-4.

Oliveira, E. e Duarte, L.M.G. 2004. Gestão da biodiversidade e produção agrícola: o Cerrado goiano. Cad. Ciênc. Tecnol., 21: 105-142.

Panea, B., Sañudo, C., Olleta, J.L. y Sierra, I. 2010. Caracterización de la canal y la carne de la raza bovina Menorquina. Arch. Zootec., 59: 467-470.

Perea, J., García, A., Acero, R., Valerio, D. y Rodríguez, V. 2007. Caracterización productiva del vacuno ecológico en Andalucía. Arch. Zootec., 56: 517-521.

Ramos Filho, F.S.V. 2006. Qualidade na cadeia da carne bovina: o caso da carne orgânica. Dissertação (Mestrado em Desenvolvimento, Agricultura e Sociedade). Instituto de Ciências Humanas e Sociais. Universidade Federal Rural do Rio de Janeiro. Rio de Janeiro. 167 pp.

Santilli, J. 2006. As indicações geográficas e territorialidades específicas das populações tradicionais: povos indígenas e quilombolas. Em: Lages, V., L. Lagares, C.L. Braga (Orgs.). 2006. Valorização de produtos com diferencial de qualidade e identidade: indicações geográficas e certificações para competitividade nos negócios. $2^{\mathrm{a}}$ ed. Brasília. Sebrae. pp. 203-217.

Silva, A.L., Cerdan, C. e Velloso, C.Q. 2008. Boas práticas para indicações geográficas: A ação coletiva como elemento central na sua implementação. Em: Pimentel, L.O., S.O. Boff, F.S. Del'Omo. Propriedade intelectual: gestão do conhecimento, inovação tecnológica no agronegócio e cidadania. Fundação Boiteux. Florianópolis. pp. 227-235. 